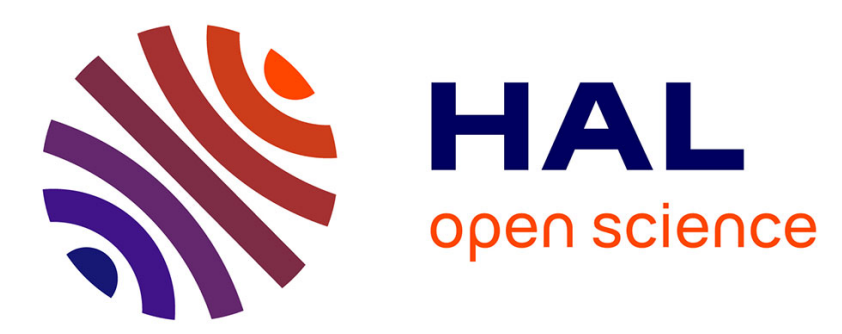

\title{
The Role of Oxygen on the Growth of Palladium Clusters Synthesized by Gas Aggregation Source
}

William Chamorro-Coral, Amaël Caillard, Pascal Brault, Pascal Andreazza, Christophe Coutanceau, Steve Baranton

\section{- To cite this version:}

William Chamorro-Coral, Amaël Caillard, Pascal Brault, Pascal Andreazza, Christophe Coutanceau, et al.. The Role of Oxygen on the Growth of Palladium Clusters Synthesized by Gas Aggregation Source. Plasma Processes and Polymers, 2019, 16 (7), pp.e1900006. 10.1002/ppap.201900006 . hal02093151

\section{HAL Id: hal-02093151 \\ https://hal.science/hal-02093151}

Submitted on 8 Apr 2019

HAL is a multi-disciplinary open access archive for the deposit and dissemination of scientific research documents, whether they are published or not. The documents may come from teaching and research institutions in France or abroad, or from public or private research centers.
L'archive ouverte pluridisciplinaire $\mathbf{H A L}$, est destinée au dépôt et à la diffusion de documents scientifiques de niveau recherche, publiés ou non, émanant des établissements d'enseignement et de recherche français ou étrangers, des laboratoires publics ou privés. 


\section{The Role of Oxygen on the Growth of Palladium Clusters Synthesized by Gas Aggregation Source ${ }^{a}$}

William Chamorro-Coral ${ }^{1 *}$, Amaël Caillard ${ }^{1}$, Pascal Brault ${ }^{1}$, Pascal Andreazza $^{2}$, Christophe Coutanceau $^{3}$, Stève Baranton ${ }^{3}$

${ }^{1}$ GREMI, UMR 7344 CNRS-Université d'Orléans, BP6744, 45067 Orléans cedex 2, France

${ }^{2}$ ICMN, CNRS, Université d'Orléans, URM7374, 1b rue de la Férollerie, F-45071 Orléans, France

${ }^{3}$ IC2MP UMR7285 CNRS - Université de Poitiers, TSA 51106, 86073 Poitiers cedex 9, France

E-mail: william.chamorro-coral@univ-orleans.fr

Palladium clusters are grown using a gas aggregation source coupled to magnetron sputtering with oxygen as reactive gas. Clusters with a mean size between $2.6 \mathrm{~nm}$ and $3.3 \mathrm{~nm}$ are obtained. Oxygen enhances the deposition rate by a factor 3 (from 4 to $11 \mathrm{mg} \mathrm{h}^{-1} \mathrm{~cm}^{-2}$ ) at the expense of the formation of larger clusters and the modification of the cluster composition. An increase of the oxygen flow rate induces a transition from $\mathrm{Pd}$ to $\mathrm{PdO}$, this transition is followed by the formation of 2D structural defects in the crystals as displayed by Grazing Incidence X-ray Diffraction and HRTEM micrographs. Oxygen interacts with both the target and the sputtered atoms highlighting that the target oxidation could be considered as the key step that drives the cluster growth processes. 


\section{Introduction}

Production of nano-sized clusters is attractive because of their outstanding advantages in different applications (i. e. microelectronics, heterogeneous catalysis, medicine, etc.) ${ }^{1,2}$ where small size and high crystal quality of clusters are needed. Magnetron sputtering is a standard process in the coatings industry. When sputtering is used as metal vapor source in a gas aggregation source (GAS) it is possible to produce a continuous beam of nanoclusters in the range of 1-10 $\mathrm{nm}$ for a wide variety of metals. ${ }^{3-6}$ The formation of clusters in a GAS is due to the condensation of sputtered atoms in the gas phase following three main steps: metallic vapor supersaturation, nucleation and cluster growth. In GAS, the mean free path of the sputtered atoms between each collision with the gas atoms is less than $1 \mathrm{~mm}$ due to the large GAS pressure (few tens of $\mathrm{Pa}$ ). Thus the sputtered atoms rapidly reach an energetic equilibrium with the gas phase called thermalization, leading to metallic atom vapor saturation. ${ }^{3}$ Thermalized metallic atoms are transported through the gas phase by a diffusion mechanism ${ }^{7}$ and the nucleation step can start with the formation of metal dimers through a three-body mechanism. ${ }^{8-}$

${ }^{10}$ Cluster growth continues by attachment of free atoms or by coalescence with other clusters (two-body mechanism). ${ }^{9}$ Both processes occur permanently due to the continuous target sputtering and the continuous gas flow. In conventional GAS setup, the formation of clusters by addition, coalescence or coagulation only occurs in a limited space called aggregation zone close to the magnetron; the time that clusters spend in the aggregation zone is called residence time. Experimental parameters such as total pressure, target power, aggregation zone length and addition of inert $(\mathrm{He})$ or reactive $\left(\mathrm{O}_{2}\right.$ or $\left.\mathrm{N}_{2}\right)$ gases have a strong influence in the formation of clusters. ${ }^{3}$

By the introduction of a magnetron in the GAS chamber, the deposition rate has been considerably increased ${ }^{11}$ but remains still limited to a few $\mathrm{mg}$ per hour. Moreover, for applications such as the construction of 2D lattice patterns or quantum dot (QD) devices, a wide 
size dispersion of clusters (relative standard deviation $>10 \%$ ) can be detrimental. ${ }^{12-15}$ Filtering clusters by mass/size using a quadrupole mass spectrometer (QMS) can narrow the size distribution but the mass filtering leads also to a strong decrease of cluster deposition rate ${ }^{11,12}$ down to values close to $0.1 \mathrm{mg}$ per hour for $\mathrm{Au}_{300}(\sim 1 \mathrm{~nm})$ clusters. ${ }^{11}$ This low deposition rate represents a bottleneck for industrial applications. In the particular case of commercial catalyst fabrication as an example, the metal loading is typically comprises between 1 to few tens wt $\%$, which would require very long time to produce few grams of catalyst. Interestingly, the addition of small amounts of a reactive gas was shown to enhance the clusters deposition rate from different metals such as $\mathrm{Ti}, \mathrm{V}, \mathrm{Cu}$ or $\mathrm{W}$ by promoting the formation of clusters. However, it also involves variations on the chemical composition. ${ }^{18-20}$ The addition of a reactive gas during sputtering changes the target surface state, leads to three regimes (metallic, transition and compound regimes) and influences the flow of sputtered atoms..$^{21-24}$ The metallic to compound regime transition induces a strong variation of the discharge voltage (increase or decrease according to the system) and changes in the deposition rate and gas pressure.. The critical gas flow rate to reach the transition regime depends on the target material, reactive gas, working pressure, pumping speed and the sputtering yield (that depends on the discharge current and the magnetic configuration).

In the present study, we have focused on the synthesis of palladium clusters because of their outstanding performance as catalyst for the electro-oxidation of small organic molecules. ${ }^{2,25} \mathrm{Pd}$ clusters were already produced by GAS assisted by magnetron sputtering. ${ }^{26,27}$ In these previous studies, the growth mechanism and the cluster size were related to the main experimental parameters. Others studies have shown the effect of reactive environments, for example on Pd subnanometric clusters exposed to $\mathrm{H}_{2}$ and $\mathrm{O}_{2}{ }^{27-32}$ or Pd surfaces exposed to $\mathrm{O}_{2}{ }^{33-36}$ However, an open question, still remains: how the presence a reactive gas in the GAS chamber could affect the nanostructure and the chemical composition of Pd clusters during their growth. Since oxygen is expected to alter the sputtering process, the physics of plasma and thermodynamics 
and kinetics of the growth of clusters, the aim of this work is to contribute to the understanding of the role of oxygen addition in the formation of the Pd-based clusters and its effect on their mean size, size distribution, composition and crystallographic structure. These data are of paramount importance because they rule the physicochemical properties of materials and therefore their (electro)catalytic properties for further applications.

\section{Experimental Section}

The experimental setup is based on a commercial gas aggregation source Nanogen 50 from Mantis Deposition Ltd. The aggregation source chamber is a cylinder with an inner diameter of $130 \mathrm{~mm}$ and a total length of $20 \mathrm{~cm}$. An outlet orifice with a diameter of $5 \mathrm{~mm}$ is located at the cylinder extremity having the shape of a dome. A magnetron is placed inside the GAS chamber with the target facing the outlet orifice. The magnetron can be approached or moved back from the outlet orifice thanks to a UHV linear transfer mechanism. As the dome has a hemispherical shape, gas flow parameters such as density and velocity undergo strong variations near the orifice. ${ }^{37}$ The distance between the magnetron and the beginning of the dome curvature, denoted $d_{\mathrm{mo}}$, could be varied between 0 and $10 \mathrm{~cm}, 0 \mathrm{~cm}$ being the closest position to the orifice. As the dome part has a length of $4 \mathrm{~cm}$, a $d_{\text {mo }}$ value of $0 \mathrm{~cm}$ means that the real distance between the magnetron and the orifice is $4 \mathrm{~cm}$. The distance $d_{\text {mo }}$ is fixed to $6 \mathrm{~cm}$ for most of the experiments presented in this study except when another $d_{\text {mo }}$ values are specified.

The GAS chamber is connected to the UV deposition chamber pumped by a single $500 \mathrm{~L} \mathrm{~s}^{-1}$ turbomolecular pump allowing to achieve a base vacuum of $10^{-4} \mathrm{~Pa}$ in the deposition chamber and of $10^{-2} \mathrm{~Pa}$ in the GAS chamber (by pumping through the orifice). Argon is used as carrier gas. Metallic vapor is obtained by the sputtering a Pd target of 2 inches in diameter $(99.99 \%$ purity) mounted on the magnetron. Using a thermopile sensor, it was detected an increase of the target temperature up to few hundreds of degrees. This could be explained by the indirect 
water cooling of the magnetron design which is less efficient for the target cooling than the direct water cooling. ${ }^{38}$ Magnetron sputtering was performed in direct current (DC) mode with a constant current intensity of 0.22 A (using an Advanced Energy Pinnacle Plus generator) which leads to a 70-100 W power range depending on the amount of oxygen. Before each series of experiments, the target was sputtered during at least 10 minutes at the same current intensity to obtain a constant target voltage. A MKS type 1739A controller coupled to a MKS Type 247 readout was used to control the argon flow rate. The oxygen flow rate was controlled with a FlowView software (through an RS232 connection) and two digital EL-FLOW meters, an F200CV-02 model for oxygen flow rates below $1 \mathrm{sccm}$ (accuracy $\pm 2 \% \mathrm{FS}$ ) and a F-201CV-100 model for oxygen flow rates above $1 \mathrm{sccm}$ (accuracy $\pm 0,5 \%$ Rd plus $\pm 0,1 \% \mathrm{FS}$ ). Argon flow rate was fixed to 100 standard cubic centimeters per minute $(\mathrm{sccm})$ and the oxygen flow rate (OFR) was varied in the range from 0 to $10 \mathrm{sccm}$ (meaning a reactive gas admixture up to $9 \%$ ), corresponding to a total pressure ranging from $38 \mathrm{~Pa}(\mathrm{OFR}=0)$ to $47 \mathrm{~Pa}(\mathrm{OFR}=10 \mathrm{sccm}$ and plasma on). The total pressure $P_{\text {total }}$ was measured in the GAS chamber with a Pfeiffer PKR 251 gauge, the $\mathrm{O}_{2}$ partial pressure $P_{\mathrm{O}_{2}}$ was calculated as the difference between the total pressure at any OFR value and the pressure at an OFR value of $0 \mathrm{sccm}$. The oxygen flow rates are divided in two sets of values: below $1 \mathrm{sccm}$ (called region A) and above $1 \mathrm{sccm}$ (called region B). The pumping speed in the GAS chamber is $4.5 \mathrm{~L} \mathrm{~s}^{-1}$.

A quadrupole mass spectrometer QMS (MesoQ from Mantis Deposition Ltd) is connected to the deposition chamber and placed $30 \mathrm{~cm}$ in front of the GAS chamber orifice. A metallic grid (biased at $+18 \mathrm{~V}$ ) placed at the end of the quadrupole collects the negatively charged cluster, allowing obtaining the in situ cluster mass distribution. The size distribution was evaluated assuming clusters with spherical shape and assuming a density for clusters equal to that of Pd bulk material $\left(d=12.02 \mathrm{~g} \cdot \mathrm{cm}^{-3}\right.$ at $\left.20^{\circ} \mathrm{C}\right)$. This last approximation is not accurate in the case of changes in the Pd clusters composition. However, considering the limit case where the clusters are entirely composed of $\mathrm{PdO}$, the cluster size will be underestimated by a factor of only 0.89 . 
This is only valid assuming that clusters acquire only one negative charge after passing through the plasma. From the size distribution curve, a set of four parameters can be obtained: the grid current intensity $\left(I_{\mathrm{OFR}}\right)$ corresponding to each OFR value, the mean size $(D)$ of Pd clusters (given after fitting of the size distribution), the relative size dispersion $(\Delta D / D)$ and the deposited mass from the integral of the mass distribution curves (denoted to as intensity*mass).

An external data recorder (DAS 500 from Sefram) was used to follow the pressure in the GAS chamber, the discharge voltage $V_{d}$ and the current collected on the QMS grid ( $\left.I_{\mathrm{OFR}}\right)$.

Clusters were deposited onto N-type/Phosphorus doped Si (100) substrates and onto carboncoated $\mathrm{Cu}$ TEM grids (300 mesh, SPI) for further characterizations. Substrate was placed in the deposition chamber between the GAS chamber and the QMS in a mobile holder at a fixed distance of $9 \mathrm{~cm}$ from the outlet orifice. After each deposition the substrate holder is moved back in order to perform QMS measurements without blocking the cluster beam trajectory. For each OFR value, the deposition rate $\mathrm{d}_{\mathrm{rOFR}}$ is measured prior to deposition experiments using a quartz microbalance with a $6 \mathrm{MHz}$ sensor quartz crystal (Maxtek TM-350) placed instead of the substrate. This deposition rate is obtained assuming the density and the acoustic impedance of pure Palladium.

Oxygen incorporated in the deposited clusters was quantified by Nuclear Reaction Analysis (NRA) with a $\mathrm{D}^{+}$beam of $900 \mathrm{keV}$ and a scattering angle of $166^{\circ}$. Grazing Incidence X-ray diffraction (GIXD) measurements were performed with a Panalytical diffractometer with a $\mathrm{Cu}$ $\mathrm{K} \alpha$ X-ray source $\left(1.5418 \AA\right.$ A). X-ray beam incident angle was fixed at $0.5^{\circ}$ to limit the penetration depth in the deposited cluster layer. The deposition time of Pd clusters onto Sisubstrates is different for each sample (between 60 to $120 \mathrm{~s}$ ) in order to keep an average thickness of approximately $250 \mathrm{~nm}$. Measurements were done in a large $2 \theta$ range from 25 to $80^{\circ}$ although the $\mathrm{q}$ range that includes the main diffraction peaks of metallic and oxidized Palladium phases is only from 20 to $35 \mathrm{~nm}^{-1}$ (corresponding to $2 \theta$ range from 30 to $50^{\circ}$ ). The extracted data were compared with simulated spectra coming from Debye formula calculations 
on several models of clusters with different sizes and different levels of structural disorder or fault (metallic cluster, oxide domains and oxide cluster). ${ }^{39-41}$

High resolution transmission electron microscopy (HRTEM) investigations were carried out using a JEM-ARM 200F Cold FEG TEM/STEM operating at $200 \mathrm{kV}$ and equipped with a spherical aberration $(\mathrm{Cs})$ probe and image correctors (point resolution $0.12 \mathrm{~nm}$ ).

\section{$3 \quad$ Results and Discussion}

\subsection{Effect of the $\mathrm{O}_{2}$ addition on the discharge voltage and the GAS chamber pressure}

As explained in the introduction section, the discharge voltage $\left(V_{\mathrm{d}}\right)$ and the total pressure in the aggregation chamber give an insight about the reactive sputtering process. In Figure 1, the discharge voltage is plotted as a function of the OFR values. A rise of the discharge voltage (Figure 1a) from $335 \mathrm{~V}$ at $0 \mathrm{sccm}$ to $430 \mathrm{~V}$ at $1 \mathrm{sccm}$ reveal a progressive target surface oxidation process. This $V_{\mathrm{d}}$ increase after addition of $0.03 \pm 0.02 \mathrm{sccm}$ reveals the absence of a metallic region above this OFR, which could be explained by the low pumping speed in the GAS chamber and the resulting partial pressure of oxygen $\left(\mathrm{P}_{\mathrm{O}_{2}}=0.08 \mathrm{~Pa}\right)$ that can be high enough to start the Pd target oxidation. ${ }^{24}$ Two sub-regions can be differentiated in Figure 1a: the first one below and the second one above $0.60 \mathrm{sccm}$. In the first sub-region, the discharge voltage has a striking rise that slows down in the following sub-region. The $V_{\mathrm{d}}$ increase rate (denoted Derivative $V_{\mathrm{d}}$ in the inset of Figure 1a) reaches a maximum for an OFR value of 0.15 $\mathrm{sccm}\left(\mathrm{ca} .350 \mathrm{~V} \mathrm{sccm}^{-1}\right.$ ) and then decreases to a value lower than $10 \mathrm{~V} \mathrm{sccm}^{-1}$ above $0.60 \mathrm{sccm}$. The shape followed by the $V_{\mathrm{d}}$ with respect to the OFR can be compared to the total surface coverage in an adsorption process observed in typical isotherm curves $;{ }^{42}$ this indicates that the target poisoning (by oxygen) is probably complete at $0.60 \mathrm{sccm}$. Therefore, between 0 and 0.60 sccm, the sputtering process operates in the transition zone (TZ). The voltage increase is related 
to the change of the secondary electron emission yield $(\gamma)$, that is specific for each sputtered material and is inversely proportional to $V_{\mathrm{d}}{ }^{24}$ In the transition zone, $\gamma$ is the sum of the metal $\left(\gamma_{m}\right)$ and the oxide $\left(\gamma_{o x}\right)$ electron emission yields multiplied by the metallic and oxidized target surface fractions, respectively. For Palladium, it is expected that $\gamma_{o x}$ has a lower value than $\gamma_{m}$ as for other noble metals such as $\mathrm{Au}$ and $\mathrm{Pt}^{43}$ which explains the discharge voltage increase. The increase of the oxidized target surface fraction also affects the sputtering process leading to a decrease of the sputtering rate. However, the increase of the $V_{\mathrm{d}}$ value (up to $30 \%$ in region A) involves an increase of the kinetic energy of the bombarding $\mathrm{Ar}^{+}$ions, that could lead further to a higher sputtering rate. Therefore, two processes are in competition in the transition zone, which could affect the process of cluster formation (discussed later).

Above $0.6 \mathrm{sccm}$, the system can be considered in the compound zone. In region B of Figure 1b, the voltage increase rate is close to $10 \mathrm{~V} \mathrm{sccm}^{-1}$ up to $4 \mathrm{sccm}$ and then decreases to about $2 \mathrm{~V}$ $\mathrm{sccm}^{-1}$. This decrease of voltage increase rate could be due to a change in experimental procedure. Indeed, the OFR was increased at a rate of $0.3 \mathrm{sccm} . \mathrm{min}^{-1}$ and $0.5 \mathrm{sccm} \cdot \mathrm{min}^{-1}$ below and above 4 sccm, respectively.
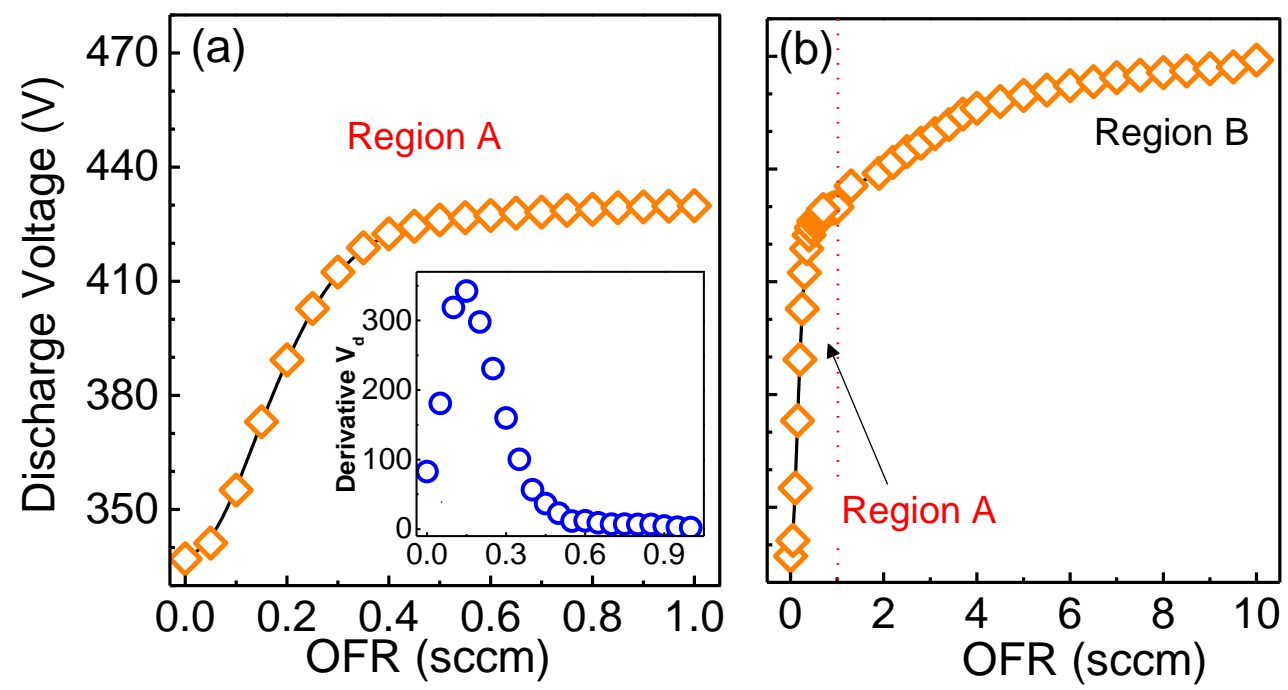

Figure 1. Effect of the OFR on the discharge voltage (orange) (a) in region A and (b) in region $\mathrm{A}+\mathrm{B}$. Inset: Derivative of the discharge voltage (blue) in the region A. 
Figure 2 shows the changes in total pressure $\left(P_{\text {total }}\right)$ and $\mathrm{O}_{2}$ partial pressure $\left(P_{\mathrm{O}_{2}}\right)$ in the GAS chamber as a function of the OFR. In region A, the pressure profile presents two increases: near 0.1 and $0.7 \mathrm{sccm}$. These sudden changes are evidenced by the two maxima on the derivative curve of $\mathrm{P}_{2}$ with respect to OFR in the inset of Figure $2 \mathrm{a}$ (red squares in the main graphic and in the inset). Both pressure fluctuations in the transition zone, match respectively to the maximum of the $V_{\mathrm{d}}$ derivative, (the highest rate of $\mathrm{Pd}$ target oxidation) and to the beginning of the compound zone. In region B, the pressure increases linearly with the OFR value. It is worth to notice that in the transition zone, the average pressure increase rate is around $1.5 \mathrm{~Pa} \mathrm{sccm}^{-1}$ while after complete target surface oxidation, this rate decreases to $0.8 \mathrm{~Pa} \mathrm{sccm}^{-1}$. A different behavior is observed in classic reactive sputtering where, after the complete target oxidation, the pressure increase is higher in the compound zone. ${ }^{24}$ In a GAS set up, oxygen is not only consumed by the target surface (as in classical reactive sputtering), but also by the clusters growing close to the magnetron surface. An insight of the role of oxygen addition in the clusters growth will be discussed in the following section.
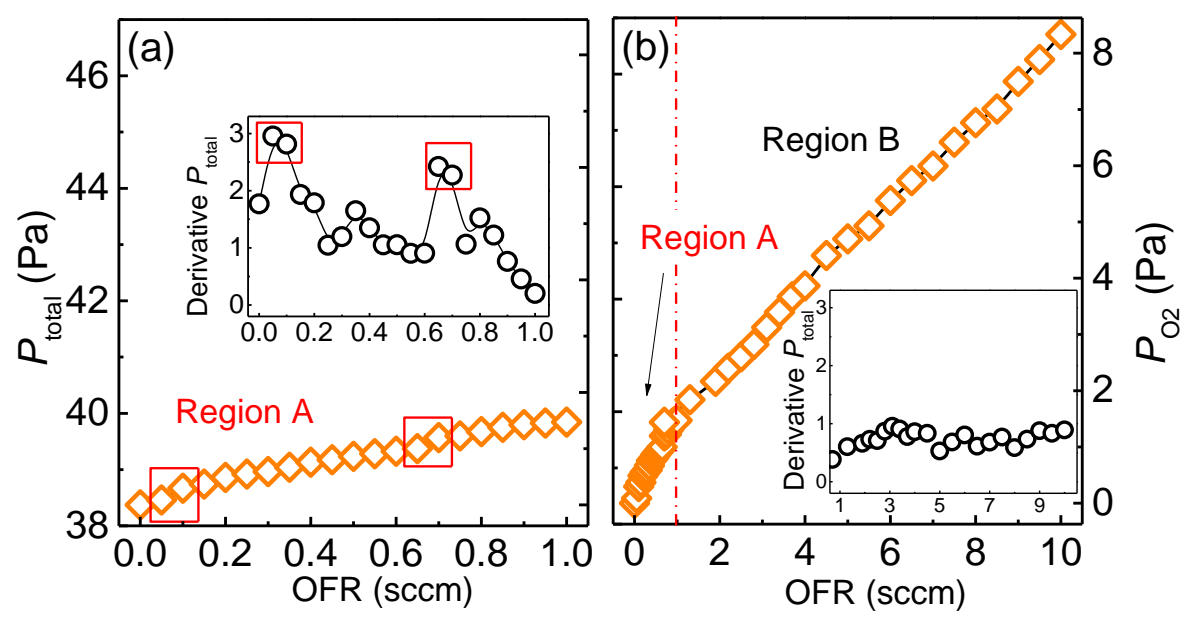

Figure 2. Effect of the OFR on $P_{t \text { tal }}$ and $P_{\mathrm{O}_{2}}$ in GAS for (a) region A and (b) region A+B.

Insets: Derivatives of the pressure in region A and B, respectively. 


\subsection{In situ characterization of the produced Pd clusters}

The present section will only investigate the effect of oxygen addition in the GAS chamber on the size and amount of formed clusters by coupling the results obtained by the QMS and the microbalance, although as mentioned above the nature and the structure of the clusters could also be affected.

Figure 3 shows the size distribution curves of Pd clusters grown at $6 \mathrm{~cm}$ for different OFR values, measured in situ by the QMS. The curves follow a lognormal distribution which is typical for growth mechanisms involving atoms attachment or coalescence. ${ }^{44,45}$ Small variations between distribution curves are observed in both regions A (Figure 3a) and B (Figure 3b), However, these variations are much less pronounced in region B than in region A.
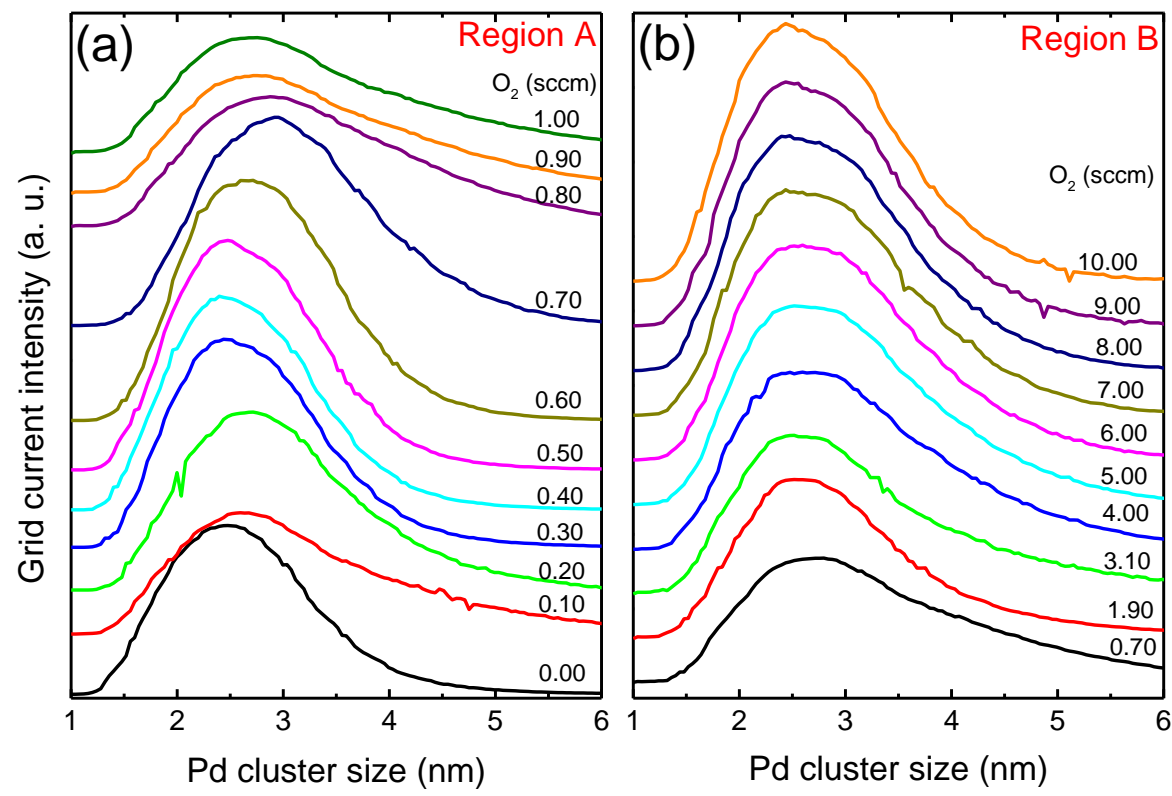

Figure 3. Y offset figures showing in situ Pd cluster size distributions measured with the QMS for different OFR in (a) region A and (b) region B.

Figure 4a shows the grid intensity $\left(I_{\mathrm{OFR}}\right)$ and the deposition rate $\left(d_{\mathrm{r}}\right)$ as a function of the OFR. Both curves are expressed as a ratio between the value at any OFR and the reference values $I_{0}$ 
and $d_{\mathrm{r}_{0}}$ that corresponds to their values without oxygen. Under these conditions, without oxygen and with a $d_{\mathrm{mo}}=6 \mathrm{~cm}$, the deposition rate $\left(d_{\mathrm{r}_{0}}\right)$ obtained by the microbalance is equal to $3.9 \mathrm{mg}$ $\mathrm{h}^{-1} \mathrm{~cm}^{-2}$. There is an oscillating behavior in both curves, $I_{\mathrm{OFR}} / I_{0}$ and $d_{\mathrm{r}} / d_{\mathrm{r}_{0}}$, ranging from 0.7 to 1.45 and from 1 to 3 , respectively, both with opposite trends: an increase of the deposition rate is associated with a decrease of the grid intensity. Indeed, as soon as oxygen is introduced, the grid intensity quickly falls from $I_{0}$ to a minimum value of $0.7 \cdot I_{0}$ for $0.1 \mathrm{sccm}$, whereas the deposition rate reaches a maximum value of $1.8 \cdot d_{\mathrm{r}_{0}}$ at $0.2 \mathrm{sccm}$ (close to $7 \mathrm{mg} \mathrm{h}^{-1} \mathrm{~cm}^{-2}$ ). A further increase of the OFR leads to an increase of the intensity up to $1.5 \cdot I_{0}$ at $0.6 \mathrm{sccm}$, corresponding to the end of the transition zone whereas a small decrease of the deposition rate down to $1.5 \cdot d_{\mathrm{r}_{0}}$ at $0.4 \mathrm{sccm}$ is observed. Finally, the grid current decreases down to $0.7 \cdot I_{0}$ for higher OFR value whereas the deposition rate reaches $2.9 \cdot d_{\mathrm{r}_{0}}$ at $0.7 \mathrm{sccm}$ (which corresponds to the maximum mass deposition rate close to $11 \mathrm{mg} \mathrm{h}^{-1} \mathrm{~cm}^{-2}$ ). similar behaviors were previously observed in the $\mathrm{Cu}-\mathrm{O}$ and $\mathrm{Ti}-\mathrm{O}$ systems where the deposition rates reached maxima at optimized OFRs. ${ }^{18,46}$ The opposite trend seems to indicate that when the number of negatively charged clusters decreases, the mass of the deposited materials increases. But, the size dispersion curves in Figure 3 reveal that a decrease of the maximum peak intensity is accompanied with an increase of the intensity at higher cluster size values. Therefore, an increase of the deposition rate when the QMS maximum intensity is decreased could be explained by the formation of larger clusters. ${ }^{18}$

To further investigate the origin of such fluctuations, the change of the integral of the mass distribution curves (denoted intensity*mass), the mean size $(D)$ and the relative size dispersion $(\Delta D / D)$ are investigated and displayed in Figure $4 \mathrm{~b}$ and $4 \mathrm{c}$. For OFR values below $0.7 \mathrm{sccm}$ the shapes of the intensity*mass curves are similar to the mass deposition rate obtained with the quartz microbalance. Nevertheless, above $0.7 \mathrm{sccm}$, the intensity*mass curve decreases while the deposition rate remains constant. This suggests that below $0.7 \mathrm{sccm}$ the population of 
clusters is mainly composed of negatively charged clusters whereas above $0.7 \mathrm{sccm}$, a higher presence of neutral or positively charged clusters could increase the total mass deposition rate. The large presence of oxygen above the transition zone in the gas phase could decrease the electron density, affecting the cluster charging process, thus, diminishing the number of negatively charged clusters.

The mean size on Figure 4c fluctuates between $2.6 \mathrm{~nm}$ and $3.3 \mathrm{~nm}$ whereas the relative size dispersion values varies between 0.28 and 0.36 . Both curves show two maxima located at 0.1 and $0.8 \mathrm{sccm}$ displaying a similar shape to that of the intensity*mass curve. Both parameter increases can be associated to the formation of bigger nanoclusters. So, the inverse relationship between the maximum of the mean size (Figure 4c) and the minimum of the grid current (Figure 4a) seems to indicate that an increase of the cluster mean size directly induces a reduction of the number of clusters formed in the TZ.

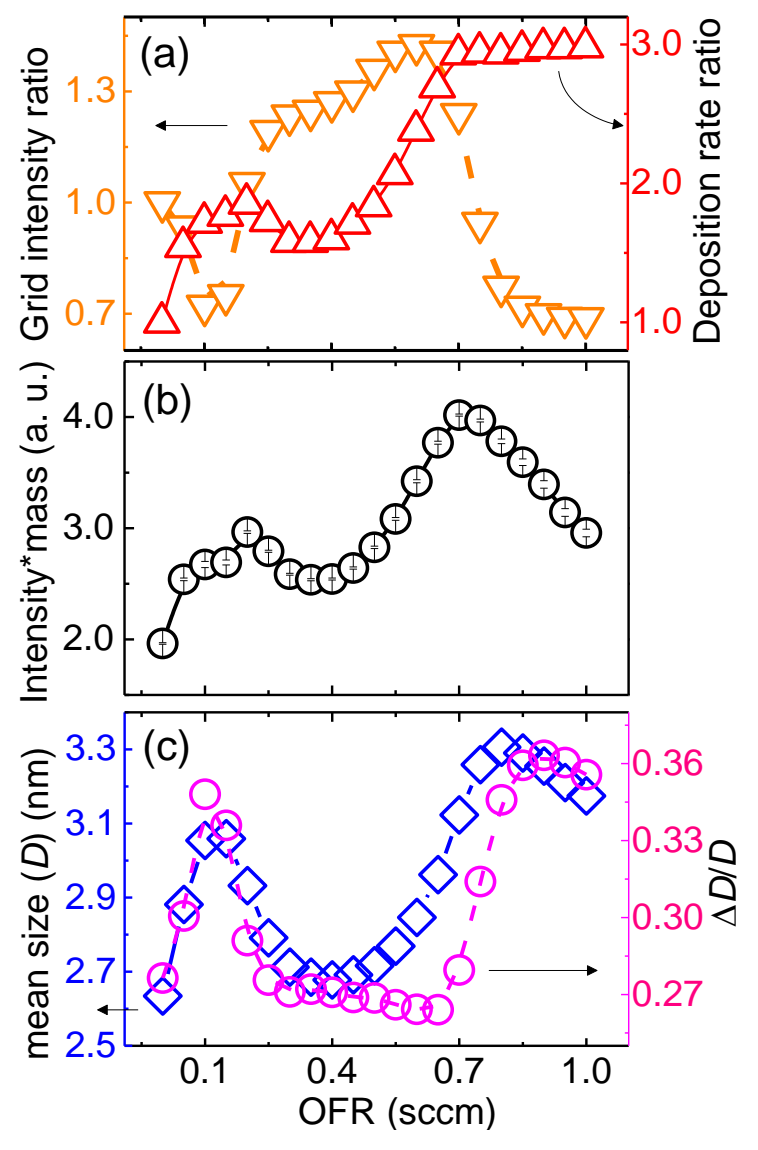


Figure 4. Effect of the OFR value in region A on (a) the grid current intensity (orange downtriangles, left axis) and on the deposition rate (red up-triangles, right axis), (b) grid intensity*mass (black circles) and (c) the mean size (blue diamonds, left axis) and the relative size dispersion (violet circles, right axis) in region $\mathrm{A}$.

To have more information about the role of oxygen in the cluster growth, the $d_{\text {mo }}$ distance is varied between 2 and $10 \mathrm{~cm}$, affecting the aggregation zone length (therefore the residence time) while the OFR is set to low values (below $0.1 \mathrm{sccm}$ ). Figure 5 shows the deposition rate $\left(d_{\mathrm{r})}\right.$ as a function of $d_{\mathrm{mo}}$ for different OFR values $(0,0.03,0.06$ and $0.1 \mathrm{sccm})$. In the absence of oxygen, the deposition rate continuously increases between 2 to $4 \mathrm{~cm}$ and above $4 \mathrm{~cm}$, it reaches a nearly constant value (four-times higher than that at $2 \mathrm{~cm}$ ). In the presence of oxygen, the deposition rate displays a maximum between 3 and $4 \mathrm{~cm}$ and above $6 \mathrm{~cm}$ decreases to reach a constant value. This indicates that at low $d_{\text {mo }}$ values (below $8 \mathrm{~cm}$ ) the deposition rate is enhanced by the oxygen addition, i.e. for low residence times. The maximum deposition rate occurs for an optimum $d_{\text {mo }}$ value that slightly decreases from 4 to $3 \mathrm{~cm}$ when the OFR value increases. At $6 \mathrm{~cm}$, the deposition rate was increased by a 1.3 factor after adding an OFR value of $0.10 \mathrm{sccm}$, while at $3 \mathrm{~cm}$, the deposition rate is 2.5 times higher for the same OFR value. 


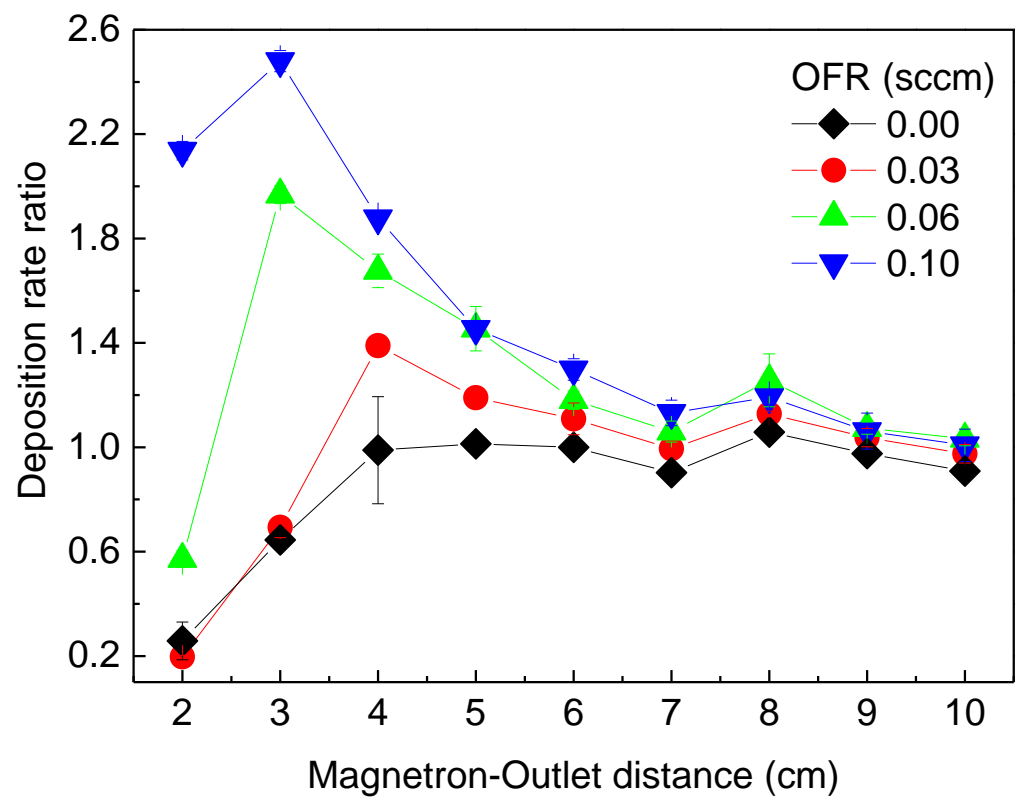

Figure 5. Influence of the OFR on the mass deposition rate for different $d_{\text {mo }}$ distances. All $d_{\mathrm{r}}$ values are normalized with respect to the one obtained at $6 \mathrm{~cm}$ and $0 \mathrm{sccm}$ (taken as reference).

Figure 6 shows the size distributions obtained by the QMS for different $d_{\text {mo }}$ values and for the same OFR values as in Figure 5. For a $d_{\text {mo }}$ value of $8 \mathrm{~cm}$, the size distribution is centered at 6 $\mathrm{nm}$ for all OFR values. This result suggests that in this case, the residence time is long enough to allow the coalescence of smaller clusters and further to reduce their number. For low $d_{\text {mo }}$ values (typically inferior to $4 \mathrm{~cm}$ ), the resulting clusters are smaller, reaching a mean size of ca. $2.5 \mathrm{~nm}$. For intermediate $d_{\text {mo }}$ values, the decrease of the number of clusters and simultaneously the broadening of the size dispersion, in which shoulder appears at larger sizes (ca. $5 \mathrm{~nm}$ ), reveal that a minimum residence time is needed to start the coalescence process. When changing the OFR value from 0 to $0.1 \mathrm{sccm}$ the grid intensity reaches a maximum at a specific $d_{\text {mo }}$, which shifts from $5 \mathrm{~cm}$ to $2 \mathrm{~cm}$ following a similar trend than the maximal deposition rate in Figure 5. Moreover, the size dispersion broadening appears at lower $d_{\text {mo }}$ values revealing that the coalescence process can start at lower residence times when adding oxygen. 

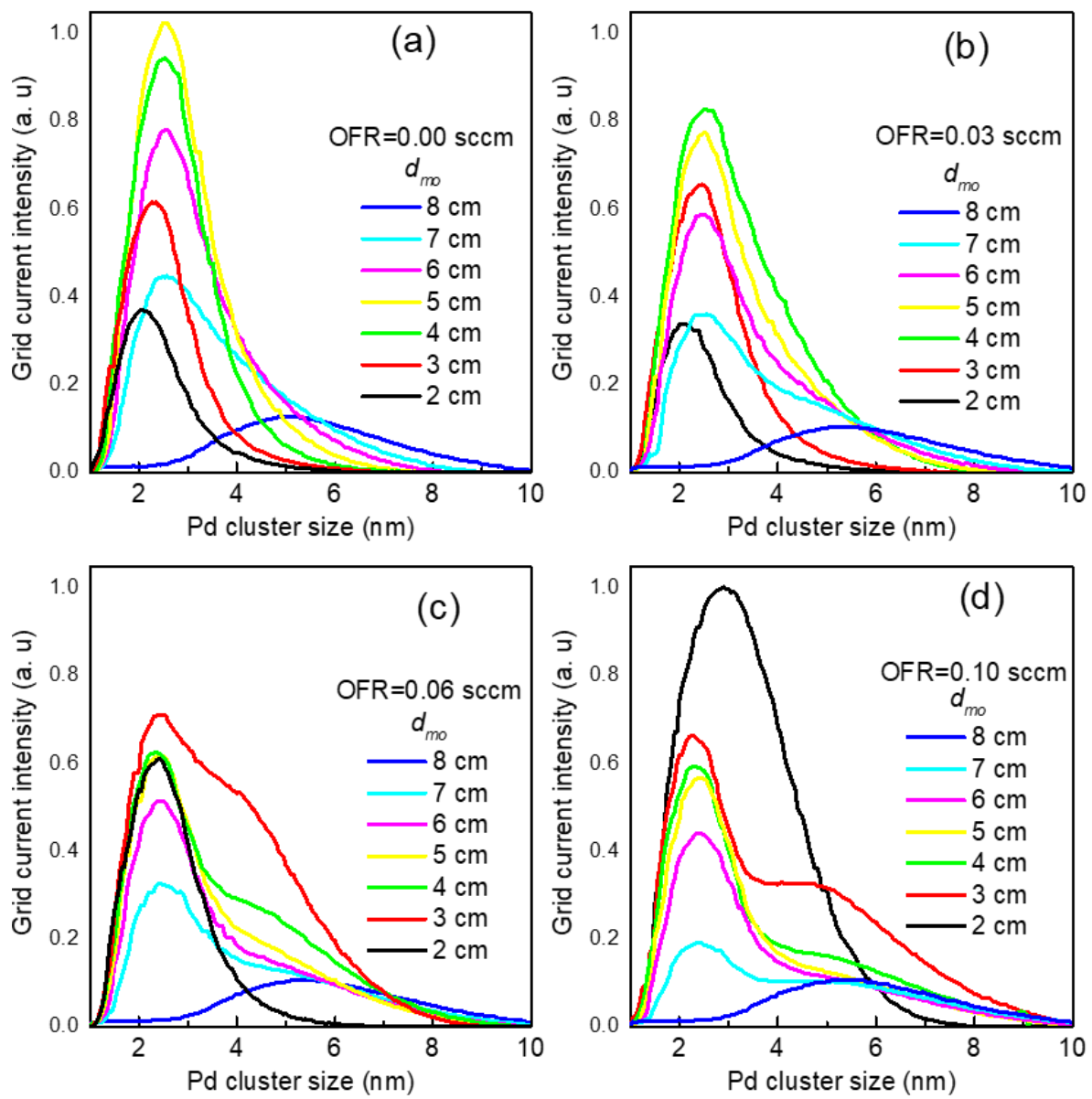

Figure 6. Influence of OFR on the size distribution for different $d_{\text {mo }}$ values. (a) OFR $=0 \mathrm{sccm}$, (b) OFR $=0.03 \mathrm{sccm}$, (c) OFR $=0.06 \mathrm{sccm}$ and (d) OFR $=0.1 \mathrm{sccm}$.

Finally, from the QMS and the microbalance results, four main observations are highlighted: (i) the mass deposition rate and the IOFR show opposite trends when oxygen is introduced in the GAS chamber, (ii) an enhancement of the mass deposition rate of Pd-based clusters, up to 11 $\mathrm{mg} \mathrm{h}^{-1} \mathrm{~cm}^{-2}$, (3 times the value obtained for $I_{0}$ ) occurs with the addition of oxygen in the GAS chamber, especially for two specific OFR values (around 0.1 and $0.7 \mathrm{sccm}$ ), (iii) the mass deposition rate increased due to the formation of larger clusters and (iv) the mass deposition rate strongly depends of the magnetron-outlet distance, the addition of oxygen at $0.1 \mathrm{sccm}$ increases the mass deposition rate by a factor 1.3 at magnetron-outlet distance of $6 \mathrm{~cm}$ but it reaches a maximum increase (by a factor 2.5) for a magnetron-outlet distance of $3 \mathrm{~cm}$. 
The origin of the increase of the mass deposition rate has been largely discussed in the literature $^{18,46-48}$, but it remains still unclear. The discharge voltage change points out two specific OFR values that come along with small pressure increases and correspond to: the maximum oxidation rate point in the transition zone and to the beginning of the compound zone. The physicochemical phenomena that occur to the gas phase near the cathode and to the target surface could be related with these two specific OFR values. The formation of large clusters could be explained by a local increase of temperature which has been recently observed in a GAS chamber ${ }^{32,49}$ and also, by plasma inhomogeneities (such as the electron temperature, electron density and plasma voltage) that appear as a result of the cluster formation and which could trap some clusters in the aggregation zone allowing the formation of larger ones (as for the Ti-O system). ${ }^{46,50}$

Local gas heating could be explained as follows: the nucleation process (a three-body mechanism) needs Ar atoms to dissipate the energy released during the formation of Pd-Pd or Pd-O bonds. However, the formation of a Pd-O bond releases more energy than the formation of a Pd-Pd bond (1.3 eV for $\mathrm{O}$ adsorption on $\mathrm{Pd}$ and between 0.5 and $1 \mathrm{eV}$ for Pd adsorption on Pd). ${ }^{51}$ This energy excess has to be dissipated by the same quantity of Ar atoms and will necessarily lead to a local gas temperature increase affecting each step of the cluster condensation (nucleation, attachment and/or coagulation rates). ${ }^{6}$ An increase of the Ar gas temperature (by any physicochemical phenomenon) in the aggregation zone will reduce the cooling effect, decrease the nuclei density and increase the quantity of free atoms available for further atom attachment processes, increasing the cluster size. Moreover, the local gas heating could modify the aggregation zone and contribute to the size distribution broadening. A recent work $^{32}$ describing the cluster growth process by molecular dynamic (MD) simulations confirms that an increase of the temperature is observed during the first steps of formation of the Pd clusters. MD simulations also showed the same behavior during the initial steps of the formation of PdO clusters but a longer period of time was needed to reach the thermal equilibrium due to 
the formation of Pd-O bonds. The first critical OFR corresponds to the maximum target oxidation rate that could match with a maximum heat release due to the formation of $\mathrm{Pd}-\mathrm{O}$ bonds. The second critical OFR value (around $0.6 \mathrm{sccm}$ ) matches with the complete Pd target oxidation, that will necessary increase the infrared radiation emitted by the target (emissivity rise), could be responsible for the second local gas heating). However, the presence of two specific OFR values inducing a mass deposition enhancement (and not only one) is still unclear. As a result, the gas heating could probably explain the deposition rate increases but the influence of the distance between the magnetron and the outlet on the gas heating and so on the growth mechanism is still under investigation.

\subsection{Nanostructure and structural characterization of Pd clusters}

The crystallinity of Pd clusters deposited onto Si (100) substrates was evaluated by GIXD. Figure 7 shows the patterns recorded on Pd clusters obtained from six different OFR values ( 0 , $0.1,0.5,1,3$, and $5 \mathrm{sccm}$ ). In the absence of $\mathrm{O}_{2}$ in the GAS, the GIDX patterns show two signals peaking at 28 and $32.2 \mathrm{~nm}^{-1}$ that correspond to the $\{111\}$ and $\{200\}$ diffraction planes of the face centered cubic (fcc) structure of palladium metal. The addition of oxygen in the GAS chamber leads to the formation of orthorhombic PdO clusters as it is observed for an OFR of 5 sccm where two signals appear at 23.8 and $29.3 \mathrm{~nm}^{-1}$. The first signal is the superimposition of two intensities of unresolved diffraction planes. The main peak of $80 \%$ in intensity located at $23.8 \mathrm{~nm}^{-1}$ corresponds to $\{101\}$ plane and the minor one of $20 \%$ intensity located at $23.5 \mathrm{~nm}^{-1}$ to the $\{002\}$ plane of a PdO structure. The second signal at $29.3 \mathrm{~nm}^{-1}$ correspond to the $\{110\}$ $\mathrm{PdO}$ diffraction plane. It is worth noticing that for an OFR value of $5 \mathrm{sccm}$, the Pd diffraction planes are weakly detected. For clusters deposited at OFR values between 0 and $0.5 \mathrm{sccm}$, a slight decrease of the Pd peak intensities along with slight peak broadenings is observed. But, for clusters prepared with larger OFR (between 0.5 and $1 \mathrm{sccm}$ ), very intense changes occur in the diffraction patterns: The $\operatorname{Pd}\{111\}$ peak intensity drops while the $\operatorname{PdO}\{101\}+\{002\}$ peak 
intensity increases dramatically (inset of Figure 7). In the case of Pd clusters prepared at $1 \mathrm{sccm}$, the Pd diffraction peaks are broad with a low intensity showing a crystallinity loss. Figure $8 \mathrm{~b}$ shows a simulation of the diffraction pattern of Pd clusters grown at an OFR value of $1 \mathrm{sccm}$ that corresponds to clusters with twins and or lattice distortions (see below). The PdO formation occurs but remains limited. The broad diffraction signals could be due to the presence of PdO coherent domains of small size. Indeed, an excellent fit of the experimental patterns is reached when considering PdO clusters with a size less or equal to $1 \mathrm{~nm}$. Other possibility is the presence of oxide domains with an amorphous character, meaning a short coherence length.

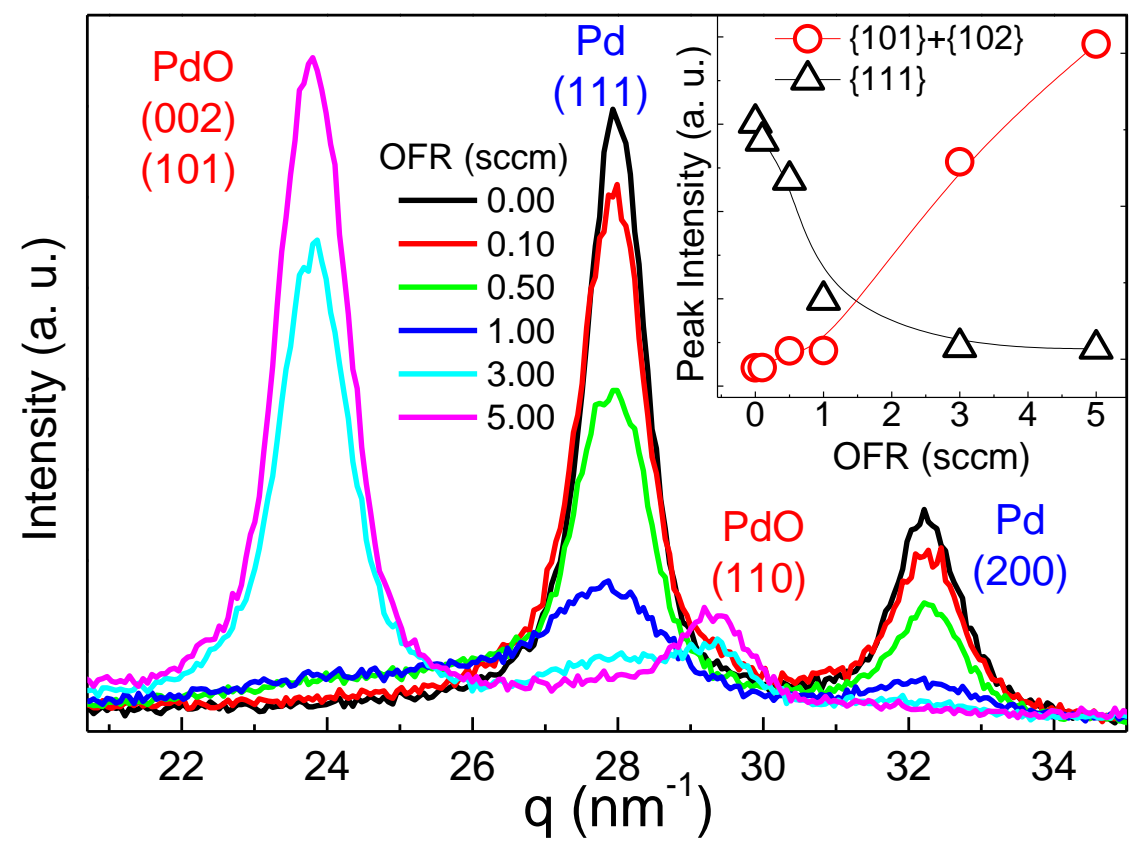

Figure 7. Grazing incidence X-ray diffraction patterns of Pd cluster deposits for different OFRs. Blue and red brackets indicate the diffraction planes for $\mathrm{Pd}$ and $\mathrm{PdO}$ respectively. Inset: Peak intensity of the $\{111\}$ Pd (black triangles) and the $\{101\}+\{102\}$ PdO (red circles) diffraction planes as a function of the OFR.

Usually, the lattice parameter of pure Pd nanoclusters is decreased in comparison with that of bulk Pd to compensate surface stresses. ${ }^{52,53}$ However, for Pd clusters deposited without oxygen, 
the simulation of scattering diffraction pattern from calculated cluster model (Figure 8a) reveals that the metallic clusters are almost perfect, free of defect measurable by GIXD, with a lattice parameter of $0.389 \mathrm{~nm}$ that corresponds to that of Pd bulk. ${ }^{54}$ The mean size of the Pd clusters is around $5 \mathrm{~nm}$ and matches the mean size from the volume distribution (as will be discussed later). In fact, the signal intensity in GIXD depends on the volume and not on the number of clusters (unlike the grid intensity). Same results were obtained with clusters prepared with an OFR value of $0.1 \mathrm{sccm}$. When increasing the OFR value up to $0.5 \mathrm{sccm}$ there is only a slight crystal expansion showing a lattice parameter of $0.390 \mathrm{~nm}$. For an OFR of $1 \mathrm{sccm}$, the lattice parameter of the clusters increases up to $0.391 \mathrm{~nm}$ and the better fit of the diffraction pattern (Figure $8 \mathrm{~b}$ ) corresponds to the simulated diffraction pattern of a distribution of clusters with a high density of stacking defects and twins, including decahedral clusters. ${ }^{55-57}$ For higher OFR values, only the lattice parameter of the orthorhombic $\mathrm{PdO}$ phase can be extracted with $a=0.3042 \mathrm{~nm}, b=0.3042 \mathrm{~nm}$ and $c=0.5351 \mathrm{~nm}$ that correspond to the bulk phase. The simulated diffraction pattern was in very good agreement with the experimental one, corresponding to well crystallized PdO clusters with a mean size of around $5 \mathrm{~nm}$ (Figure 8c). 

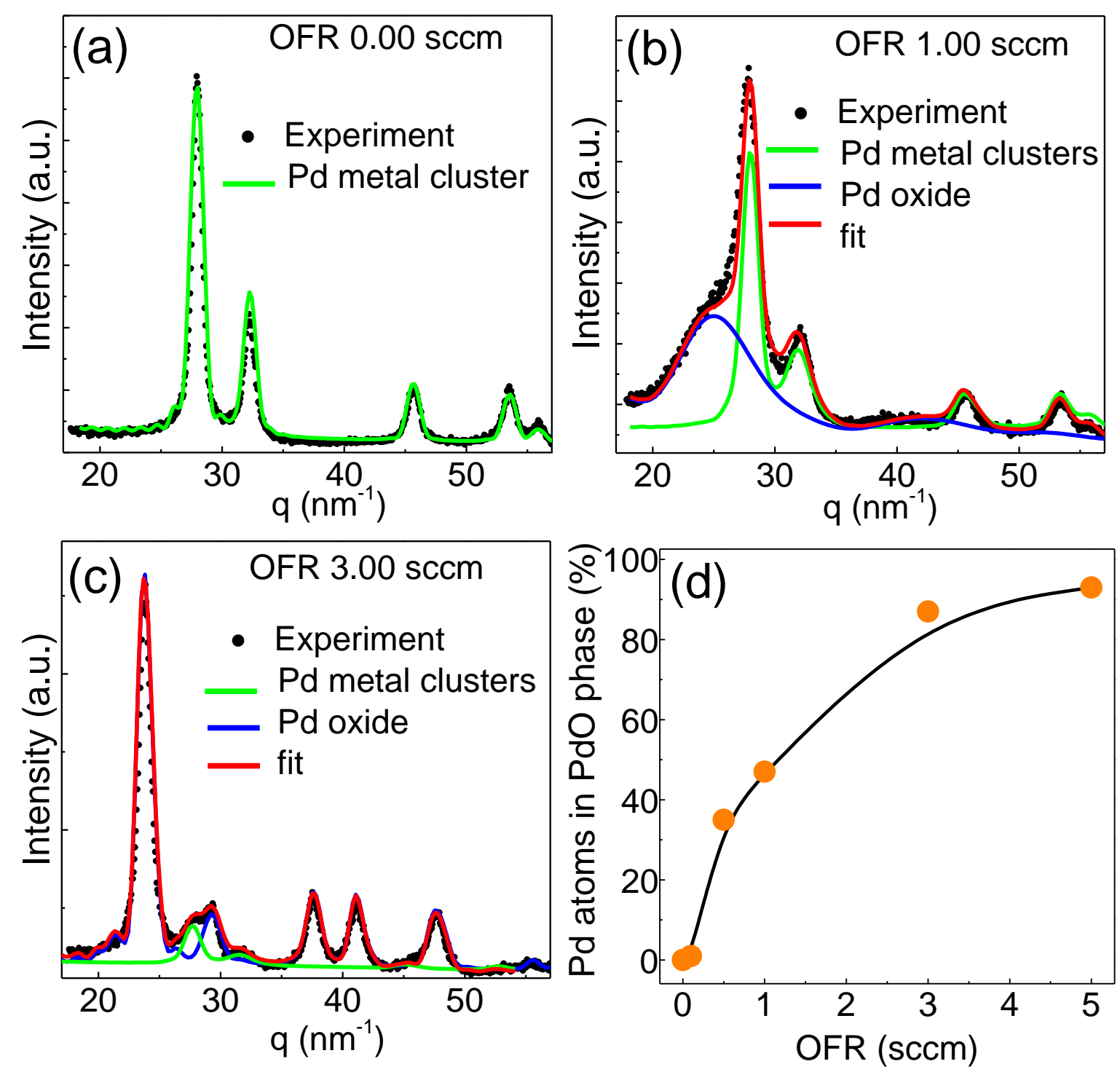

Figure 8. X-ray simulation coming from the Debbye formula ${ }^{39-41}$ showing the contributions of the Pd and PdO phases in the X-ray diffractograms at (a) $0 \mathrm{sccm}$, (b) $1 \mathrm{sccm}$ and (c) $3 \mathrm{sccm}$. (d) Percentage of $\mathrm{Pd}$ atoms in $\mathrm{PdO}$ phase with respect to the total $\mathrm{Pd}$ deposited atoms (obtained by separation of the contributions of $\mathrm{Pd}$ and $\mathrm{PdO}$ phases to each simulated X-ray diffractogram from Figure 7).

As it was mentioned before, the cluster mean size and the deposition rate were obtained assuming that the produced nanoclusters contained only Pd atoms. However, even before oxygen addition, this assumption is not accurate, because impurities such as $\mathrm{H}_{2} \mathrm{O}, \mathrm{CO}_{2}$ and $\mathrm{O}_{2}$ can be trapped in the GAS chamber. When adding oxygen in the GAS chamber, formation of 
Pd-O bonds will occur, leading to clusters containing oxygen. Oxygen coming from contamination in the GAS chamber and from the environment will be also counted. Therefore, the NRA quantification of the ${ }^{16} \mathrm{O}$ content remains mostly qualitative. Results showed a linear increase of the $\mathrm{O}$ content with the OFR value from $44 \times 10^{15}$ at $\mathrm{cm}^{-2}$ at $0 \mathrm{sccm}$ to $116 \times 10^{15}$ at $\mathrm{cm}^{-2}$ at $1 \mathrm{sccm}$ and $363 \times 10^{15}$ at $\mathrm{cm}^{-2}$ at $5 \mathrm{sccm}$. This linear behavior confirms the oxygen incorporation into the clusters when OFR increases.

The synthetized Pd-based clusters could be composed by Pd atoms at 0 (metallic) and +II (oxidized) oxidation degrees. By using X-ray diffraction measurement and the simulated spectra, it is possible to separate the contributions of the $\mathrm{Pd}(+\mathrm{II})$ atoms coming from the $\mathrm{PdO}$ phase from those of the $\mathrm{Pd}(0)$ atoms coming from the metallic Pd phase for each OFR value. It allows taking into account only the oxygen that reacted with the sputtered atoms (ruling out the contamination from environmental oxygen outside the GAS chamber) and obtaining the percentage of the $\mathrm{Pd}$ atoms constituting the $\mathrm{PdO}$ phase in the cluster as a function of the OFR value (Figure 8d). The separation of the contributions of both phases ( $\mathrm{Pd}$ and $\mathrm{PdO}$ ) were determined from simulations (Figures $8 \mathrm{a}-\mathrm{c}$ ) of diffraction patterns of Figure 7. Without $\mathrm{O}_{2}$ addition, no oxygen incorporation into the cluster is detected. An increase of the OFR value to $0.1 \mathrm{sccm}$ leads to 1 at. $\%$ of $\mathrm{PdO}$ phase; for an OFR of 0.5 the $\mathrm{PdO}$ phase ratio rises to $37 \%$ and for an OFR value of $1 \mathrm{sccm}$ it reaches $47 \%$. Increasing even more the OFR value to 3 and 5 sccm allows reaching 87 and $93 \%$ of PdO phase in the clusters. This confirms that oxygen addition changes the clusters composition and that the increase of the PdO content depends on the OFR value. Right after the transition zone, at $1 \mathrm{sccm}$ the clusters present at some extend an equilibrium between the $\mathrm{Pd}$ and the $\mathrm{PdO}$ phases, where the coherence domain length and the size distribution are similar for both phases.

Figure 9 shows TEM micrographs of Pd clusters grown at three OFR values (0, 1 and $5 \mathrm{sccm})$. From each micrograph, the number of clusters and their projected area are estimated to calculate 
the diameter and volume of clusters (assuming a spherical shape). The results are presented in two histograms for each OFR value.
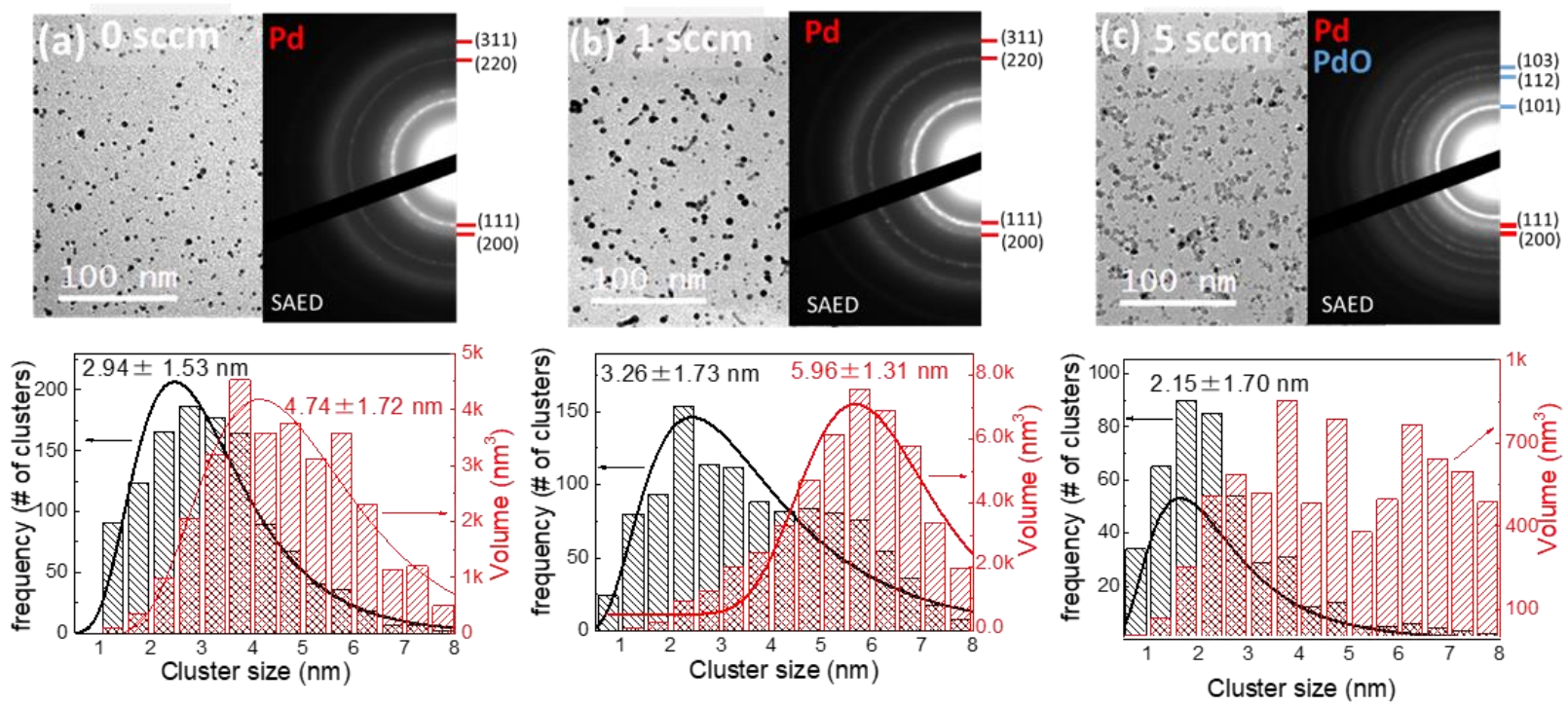

Figure 9. Pd clusters obtained for three different OFR values (a) $0 \mathrm{sccm}$, (b) $1 \mathrm{sccm}$ and (c) 5 sccm. (Top) TEM micrographs and Selected Area Electron Diffraction (in red and blue, the Pd and $\mathrm{PdO}$ diffraction planes respectively). (Bottom) Size distribution curves by frequency (number) of clusters (black curves, left axis) and by volume (red curves, right axis).

The first histograms (black bars) corresponds to the number (frequency) of clusters belonging to a given size range (called hereafter size distribution by clusters number). The second histograms (red bars) correspond to the volume (mass) of clusters belonging to a given size range (called hereafter distribution by cluster volume). The size distribution by cluster number shows the frequency to find clusters of a specific size, which can be compared to those from QMS measurements in Figures 3 and 6. The size distribution by cluster volume shows which cluster size contributes the most to the total volume and to measurements such as the deposited mass (Figures 4a and 5) and the signal intensity in the diffraction patterns in (Figure 7).

Regarding the size distribution by clusters number at $0 \mathrm{sccm}$, the size of the most frequent clusters is $2.9 \pm 1.5 \mathrm{~nm}$ while at $1 \mathrm{sccm}$ a size of $3.3 \pm 1.7 \mathrm{~nm}$ is obtained. These values are 
$15 \%$ higher than those obtained from QMS (Figure 4c). For high OFR value $(5 \mathrm{sccm})$, the size decreases strongly to $2.2 \pm 1.7 \mathrm{~nm}$, which could be explained by a stronger exothermic process during the Pd-O clusters formation than that for pure Pd clusters. ${ }^{58}$ The formation of a cluster is an exothermic process and the energy released by the formation of atomic bonds needs to be dissipated by the Ar atoms. The cluster becomes stable when it can store this excess energy by itself. Furthermore, the two-body mechanism or atom attachment can also contribute to the cluster growth and to the final size. The formation of a Pd-O bond releases more energy than a Pd-Pd bond therefore, the formation of PdO clusters takes longer to reach a thermal equilibrium, slowing the clustering process that can explain the size decrease at high OFR. ${ }^{32}$ The relative size dispersion increases when increasing the OFR from 0 to $1 \mathrm{sccm}$ as also observed in Figure $4 \mathrm{c}$ and is much higher at the OFR value of $5 \mathrm{sccm}$. In Figure 9, regarding the volume distribution, the cluster size that contributes the most to the total volume has a mean value of $4.7 \pm 1.7 \mathrm{~nm}$ for an OFR value of $0 \mathrm{sccm}$. At an OFR value of $1 \mathrm{sccm}$ the size increases to 6.0 $\pm 1.3 \mathrm{~nm}$. For an OFR value of $5 \mathrm{sccm}$, an important size dispersion is clearly observed. The size dispersion does not follow a lognormal dispersion but a multimodal distribution.

Selected area electron diffraction (SAED) patterns were recorded on the total area shown in each micrograph taken on Pd clusters synthesized at each OFR value. Analysis of the SAED patterns of Pd clusters grown at an OFR value of $0 \mathrm{sccm}$ reveals signals corresponding to the $\{111\},\{200\}\{220\}$ and $\{311\}$ crystallographic planes of the Pd fcc structure. For the clusters grown at an OFR value of $1 \mathrm{sccm}$ the signals corresponding to the Pd fcc phase are present, while the presence of the orthorhombic PdO phase is not clearly detected, conversely to observations from GIXD (Figure 7). This is probably due to the amorphous nature of the PdO phase leading to a lower signal intensity than that from GIXD. Increasing the OFR value to 5 sccm (more oxidative conditions) leads to the appearance of the three main signals at interplanar distances of $0.27 \mathrm{~nm}, 0.17 \mathrm{~nm}$ and $0.15 \mathrm{~nm}$ that could correspond to the $\{101\}$ $\{002\},\{112\},\{103\}$ and $\{200\}$ diffraction planes of the PdO phase. 
At $0 \mathrm{sccm}$, individual clusters with sizes between 1 and $2 \mathrm{~nm}$ display few crystalline planes with interplanar distance between $0.24 \mathrm{~nm}$ and $0.21 \mathrm{~nm}$ that could correspond to the $\{111\}$ and $\{100\}$ planes of Pd. For clusters with sizes between 2 and $4 \mathrm{~nm}$, the density of crystal planes is higher however the coherence domains are still small, the fast fourier transform (FFT) patterns (not shown) present a low crystal quality and distorted fcc Pd crystal cells can be detected (Figures 10a and 10b). Most of the nanoclusters grow along the [111] direction which corresponds to planes with a low surface energy; indeed, the ascending order of surface energy of planes is as follows: $(111)<(100)<(311)=(110) .{ }^{59}$ As the $(111)$ plane has the lower surface energy it is then highly probable to frequently observe this plane. Figure 10c displays a $6 \mathrm{~nm}$ cluster in between a cubic-(100) and a octahedral-(111) dominant shape ${ }^{60}$ viewed along the [110] axis zone. A zoom (Figure 10d) shows the Pd atoms matching the fcc crystal cell. The (111) interplanar distance of $0.229 \mathrm{~nm}$ shows a lattice expansion ( $a 0.396 \mathrm{~nm})$, however, for clusters of $8 \mathrm{~nm}$ the interplanar distances of $0.225 \mathrm{~nm}$ corresponds to a lattice parameter closer to the bulk value $(0.389 \mathrm{~nm})$. FFT pattern (inset of Figure $10 \mathrm{~d}$ ) shows a perfect single crystal. 

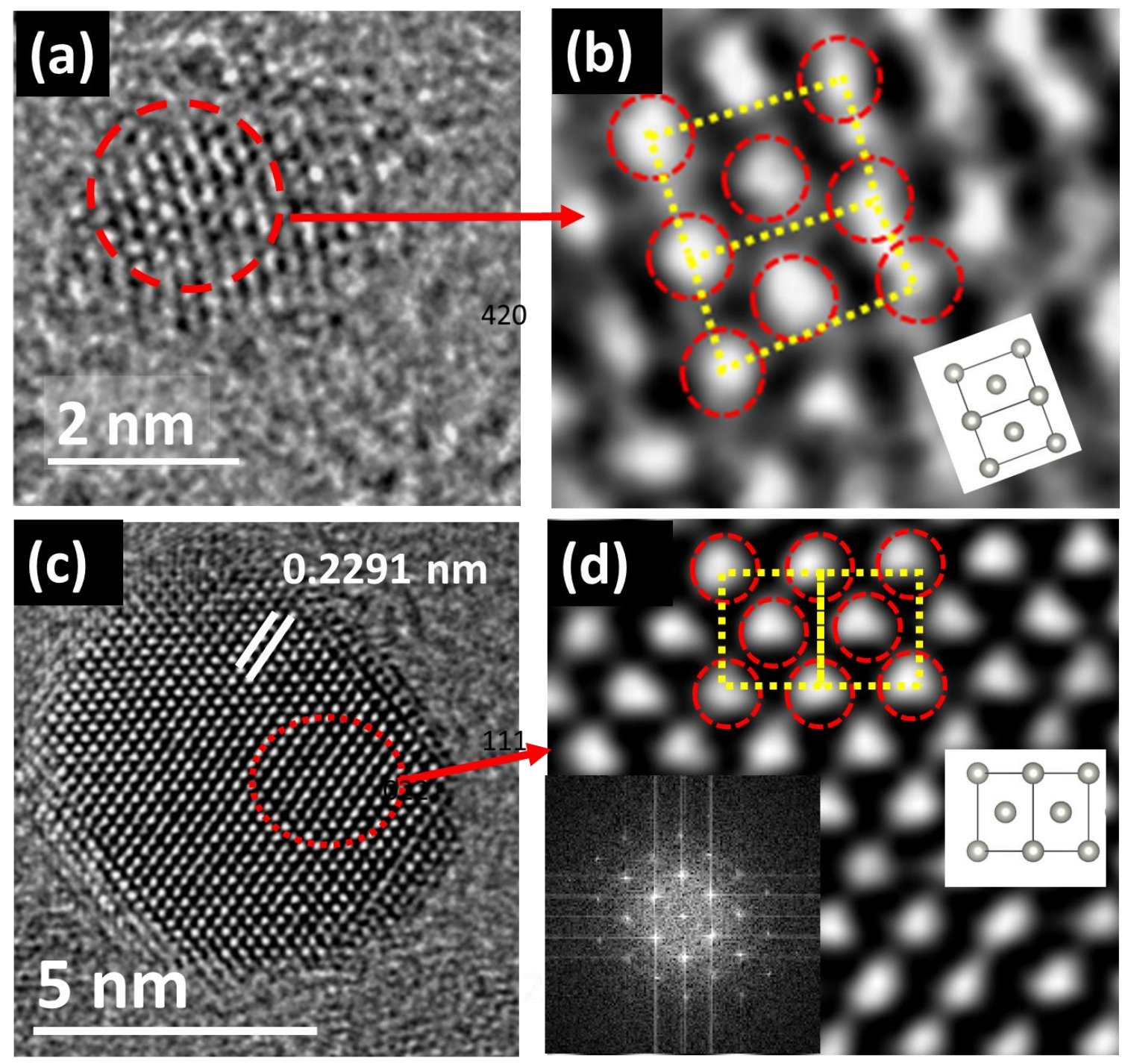

Figure 10. HRTEM micrograph of a $3 \mathrm{~nm}$ in diameter Pd cluster grown without $\mathrm{O}_{2}$ admixture

(a) and (b) zoom with a draw of the crystal cell. (c) $6 \mathrm{~nm}$ in diameter Pd cluster grown without $\mathrm{O}_{2}$ admixture and (d) zoom with draw of the crystal cell (inset: FFT pattern of Pd cluster)

Figure 11 shows a Pd cluster obtained at an OFR value of $1 \mathrm{sccm}$. A relatively good crystal quality is observed; however, the stacking faults lead to short coherence domains, decreasing the crystal quality. Figure 11a shows a Pd cluster with a slight shrinkage of the lattice parameter. The presence of twins can lead to fivefold twinned nanocluster that could correspond to the Mark's decahedron. Figure 11b shows clearly "Mark's type" facets that serve to increase the cluster stability. ${ }^{61,62} \mathrm{PdO}$ formation due to oxygen addition leads to an increase of $2 \mathrm{D}$ defects 
as stacking faults or twin boundaries that could be related to as a form to release internal strains. X-ray Diffraction and TEM SAED patterns confirmed that the clusters grown at an OFR of 5 sccm are mostly composed of the PdO phase. Figure 12a shows a PdO cluster with a high crystal quality and interplanar spacings of $0.275 \mathrm{~nm}, 0.266 \mathrm{~nm}, 0.156 \mathrm{~nm}$ and $0.154 \mathrm{~nm}$ corresponding to the $\{002\},\{101\},\{103\}$ and $\{200\}$ family planes of the orthorhombic PdO phase ${ }^{32}$. A zoom of the cluster (Figure 12b) shows the position of the Pd atoms (gray) and, as the oxygen atoms are not detected, the expected position of the oxygen atoms (green) in the orthorhombic crystal structure of the PdO phase. Figure 12c shows the FFT pattern of the PdO cluster with a [010] zone axis with its indexation showing an angle of $30^{\circ}$ between the $\{200\}-\{101\},\{101\}-\{103\}$ and the $\{103\}-\{002\}$ couples of crystallographic planes of the PdO phase.
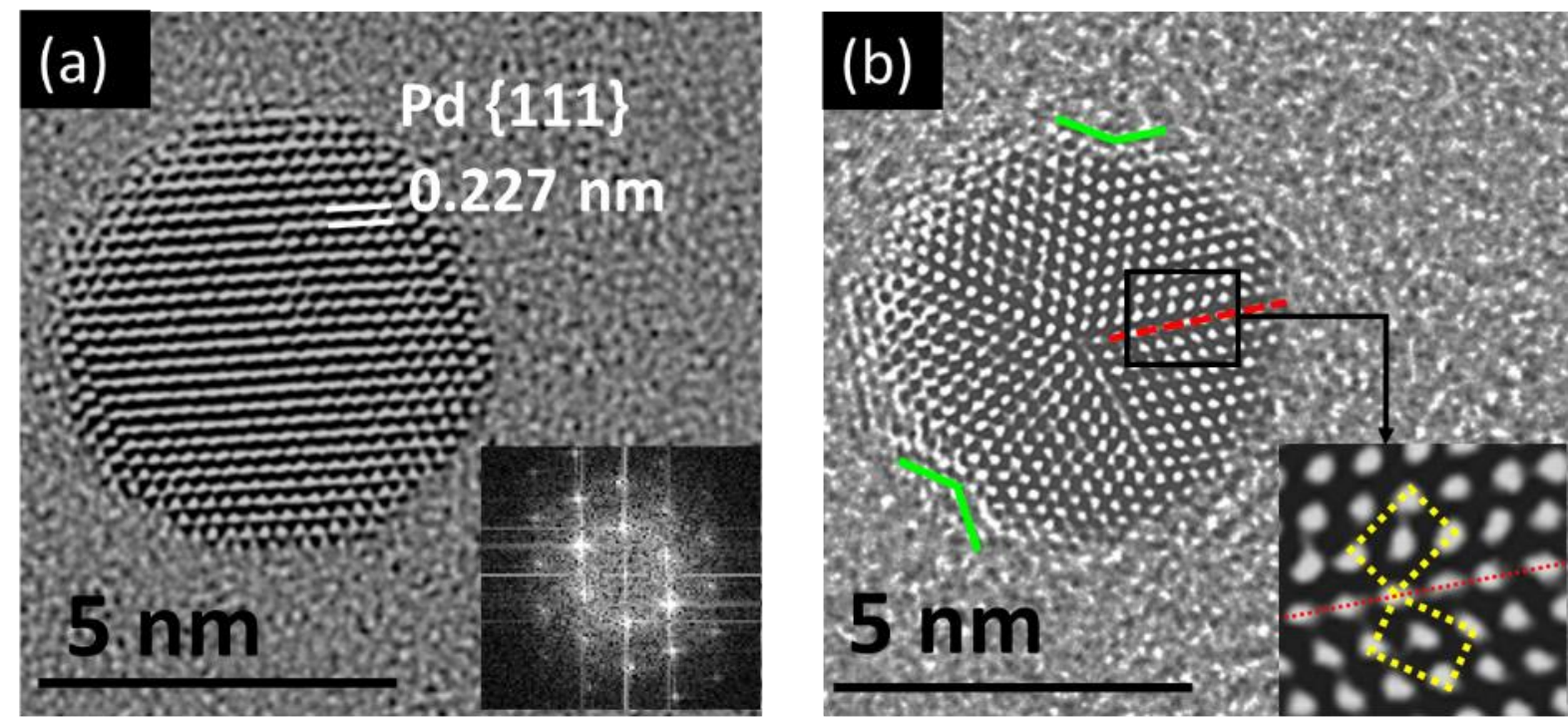

Figure 11. HRTEM micrographs of Pd clusters grown at an OFR of $1 \mathrm{sccm}$ : (a) $6 \mathrm{~nm}$ in diameter Pd clusters (Inset: FFT patern) and (b) $5 \mathrm{~nm}$ in diameter Pd clusters with a decahedral shape (red dotted lines highlight a twin boundary), green lines indicate the "Mark's type facets". Black square indicates a zoom presented in the inset. Inset: Zoom of the twin boundary). 

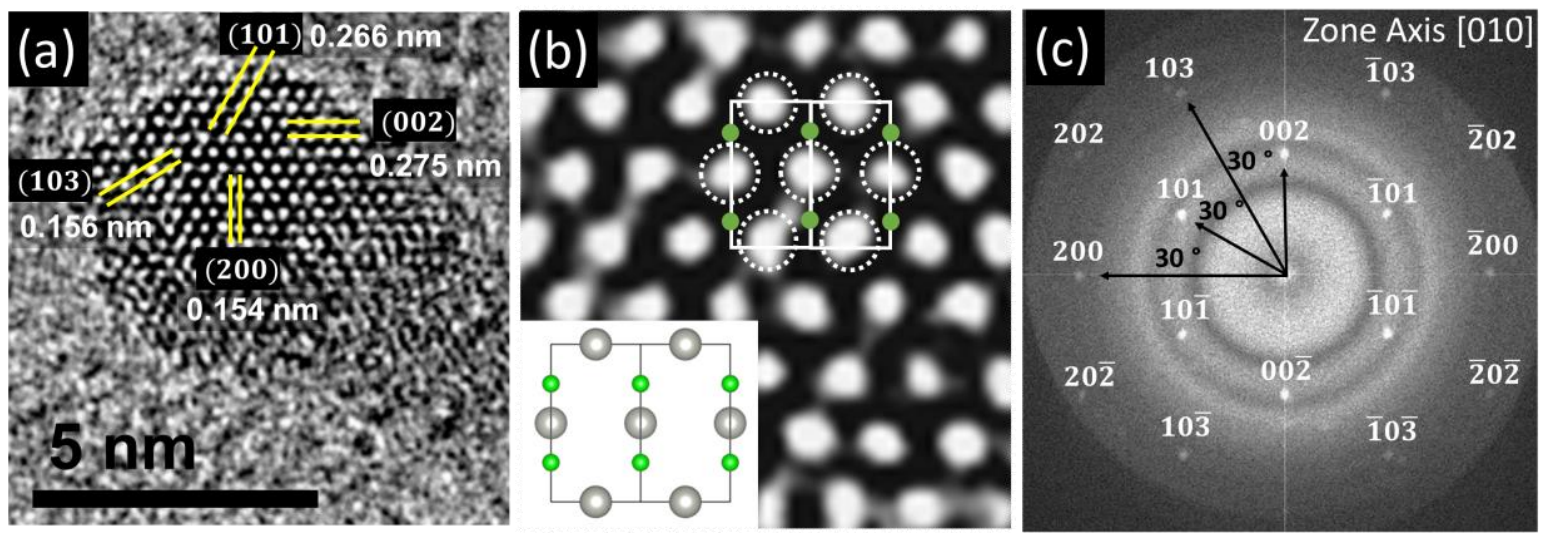

Figure 12. (a) HRTEM micrographs of a PdO cluster grown at an OFR of $5 \mathrm{sccm}$ and (b) Zoom with a draw of the PdO crystal cell. (c) Indexed PdO FFT pattern with a zome axis in the [010] direction.

The role of the oxygen during palladium cluster growth can be analyzed separately to the reactive magnetron process. As we mentioned before, the role of oxygen in palladium clusters and surfaces has been studied thoroughly, ${ }^{34-36,51}$ which allows understanding how oxygen could influence the growth of Pd clusters. According to experimental and simulation data, Pd clusters (in the gas phase) is highly reactive to $\mathrm{O}_{2}$ molecules by chemisorption processes at specific $\mathrm{Pd}: \mathrm{O}$ ratios, moreover, the released energy should be dissipated (by a buffer gas) in order to have stable clusters. ${ }^{30-32}$ In Pd surfaces, Pd crystal cell has two interstitial sites (tetrahedral and octahedral) and the oxidation of Pd surface is favored along the [110] direction because the oxygen diffuses to the bulk trough channels that connect the two interstitial sites. Moreover, oxygen adsorption in subsurface interstitial sites of the (111) surfaces is an endothermic process and could be favored due to the gas heating. ${ }^{34,51}$ In our case, in the absence of oxygen, Pd clusters start to growth favoring low energy facets as the (111). When oxygen is introduced, it readily reacts with $\mathrm{Pd}$ atoms that hinders the formation of a $\mathrm{Pd}$ fcc crystal cell, introduces internal strains and deforms the crystal cell increasing crystal defects such as stacking faults, twins and "Mark's type" facets. ${ }^{62,63}$ Below an OFR value of $0.2 \mathrm{sccm}$, i.e. in the OFR range where the target oxidation has not reached its maximum, palladium is in excess compared to 
oxygen atoms therefore, most of the cluster show the fcc structure of Pd and there is only a low proportion of $\mathrm{PdO}$ phase. Above this OFR value oxygen atoms are in excess compared to $\mathrm{Pd}$ atoms, therefore the $\mathrm{Pd}-\mathrm{O}$ bonds become more frequent. This explains the crystallinity loss and the high PdO percentage at $0.5 \mathrm{sccm}$. Increasing the OFR above the transition zone will also lead to an oxygen excess that explains the striking difference of the X-ray diffraction patterns at OFR values of 0.5 and $1 \mathrm{sccm}$.

\section{Conclusion}

In situ (quartz microbalance and quadrupole mass spectrometry) and ex situ (High resolution transmission electron microscopy and Grazing Incidence X-ray diffraction) techniques were used to understand the effect of a reactive gas $\left(\mathrm{O}_{2}\right)$ admixture on the growth and on the characteristics of Pd-based clusters synthetized with a gas aggregation source coupled to magnetron sputtering. The $\mathrm{O}_{2}$ addition in the GAS chamber enhances the mass deposition rate of Pd-based clusters up to $11 \mathrm{mg} \mathrm{h}^{-1} \mathrm{~cm}^{-2}$, especially for low magnetron-outlet distance (3-4 $\mathrm{cm}$ ) and for two specific OFR values corresponding to: (i) the maximum target oxidation rate point in the transition zone $(0.1-0.15 \mathrm{sccm})$ and to (ii) the beginning of the compound zone (0.6 - $0.7 \mathrm{sccm})$. For magnetron-outlet distances inferior to $8 \mathrm{~cm}$ and in absence of oxygen, small clusters with a mean diameter inferior to $3 \mathrm{~nm}$ were obtained. The addition of oxygen leads to the formation of larger clusters, which are responsible for the mass deposition rate enhancement. To resume, large (small) clusters lead to a lower (higher) number of clusters and to a higher (lower) mass deposition rate. The cluster composition also depends on the oxygen flow rate and confirms that even at low oxygen admixture $(<1 \%)$ the $\mathrm{PdO}$ phase is present and increase when increasing the OFR value. The addition of oxygen leads to the formation of $\mathrm{Pd}$ clusters containing Pd and PdO phases in different ratios according to the OFR value. Whereas pure $\mathrm{Pd}$ and pure $\mathrm{PdO}$ clusters present high quality crystallographic structures, the mixture of 
$\mathrm{Pd}$ and $\mathrm{PdO}$ phases in clusters leads to the formation of 2D structural defects as stacking faults and twin boundaries. These results show that oxygen plays different roles in the cluster growth process by interacting with both the target and the sputtered atoms. It is possible to say that the target oxidation along with the gas heating (rarefaction) could be considered as the key steps that drives the cluster growth process, although no direct and clear evidence of the rarefaction was given by our results.

Finally, it was demonstrated that oxygen had a strong impact in the different processes involved in the production of Pd clusters. We have shown that oxygen addition greatly enhances the deposition rate that can be industrially interesting. This increase in cluster production rate occurs at the expense of the cluster size and size dispersion and cluster composition that could be acceptable depending on the application. For further applications of such nanomaterials, and particularly in our consortium for small organic molecule electrochemical oxidation, the knowledge of such morphological and structural changes in Pd clusters induced by the sputtering conditions are of paramount importance as they rule the physicochemical properties of the clusters.

Acknowledgements: This work has been funded by French "Agence Nationale de la Recherche" under grant ANR-16-CE29-0007 (ECO-Plan project). All the authors acknowledge Hélène Lecocq, Olivier Weldling and Thierry Sauvage from CEMHTI for the NRA analysis. The authors thank Audrey Sauldubois from the CME and Jaafar Ghanbaja from IJL for the HRTEM measurements and their helpful discussions 


\section{References}

1 A. Caillard, S. Cuynet, T. Lecas, P. Andreazza, M. Mikikian, A.-L. Thomann and P. Brault, J. Phys. Appl. Phys., 2015, 48, 475302.

2 C. Coutanceau, A. Zalineeva, S. Baranton and M. Simoes, Int. J. Hydrog. Energy, 2014, 39, 15877-15886.

3 Y. Huttel, Gas-Phase Synthesis of Nanoparticles, Wiley-VCH, 2017.

4 H. Haberland, M. Karrais, M. Mall and Y. Thurner, J. Vac. Sci. Technol. Vac. Surf. Films, 1992, 10, 3266-3271.

5 C. Suryanarayana and B. Prabhu, in Nanostructured Materials (Second Edition), ed. C.

C. Koch, William Andrew Publishing, Norwich, NY, 2007, pp. 47-90.

6 O. Polonskyi, A. M. Ahadi, T. Peter, K. Fujioka, J. W. Abraham, E. Vasiliauskaite, A. Hinz, T. Strunskus, S. Wolf, M. Bonitz, H. Kersten and F. Faupel, Eur. Phys. J. D, 2018, 72, 93.

7 T. Nakano and S. Baba, Thin Solid Films, 1999, 343-344, 24-26.

8 H. Haberland, in Gas-Phase Synthesis of Nanoparticles, Wiley-Blackwell, 2017, pp. 121.

9 B. M. Smirnov, I. Shyjumon and R. Hippler, Phys. Rev. E, 2007, 75, 066402.

10 M. Grössl, M. Langenwalter, H. Helm and T. D. Märk, J. Chem. Phys., 1981, 74, 1728 1735.

11 R. E. Palmer, R. Cai and J. Vernieres, Acc. Chem. Res., 2018, 51, 2296-2304.

12 J. Liu, J. Sutton and C. B. Roberts, J. Phys. Chem. C, 2007, 111, 11566-11576.

13 S. Kabi and A. G. U. Perera, J. Appl. Phys., 2015, 117, 124303.

14 G. Conibeer, M. Green, E.-C. Cho, D. König, Y.-H. Cho, T. Fangsuwannarak, G. Scardera, E. Pink, Y. Huang, T. Puzzer, S. Huang, D. Song, C. Flynn, S. Park, X. Hao and D. Mansfield, Thin Solid Films, 2008, 516, 6748-6756.

15 C.-W. Jiang and M. A. Green, J. Appl. Phys., 2006, 99, 114902.

16 M. D. Vece, in Gas-Phase Synthesis of Nanoparticles, Wiley-Blackwell, 2017, pp. 303321.

17 K. L. Linge and K. E. Jarvis, Geostand. Geoanalytical Res., 33, 445-467.

18 A. Marek, J. Valter, S. Kadlec and J. Vyskočil, Surf. Coat. Technol., 2011, 205, S573S576.

19 T. Peter, O. Polonskyi, B. Gojdka, A. Mohammad Ahadi, T. Strunskus, V. Zaporojtchenko, H. Biederman and F. Faupel, J. Appl. Phys., 2012, 112, 114321.

20 L. Kolipaka and S. Vajda, in Gas-Phase Synthesis of Nanoparticles, Wiley-VCH Verlag GmbH \& Co. KGaA, 2017, pp. 243-268.

21 D. Depla, Magnetrons, reactive gases and sputtering, Diederik Depla, 2013.

22 P. J. Kelly and R. D. Arnell, Vacuum, 2000, 56, 159-172.

23 R. Schelfhout, K. Strijckmans, F. Boydens and D. Depla, Appl. Surf. Sci., 2015, 355, 743-747.

24 D. Depla and S. Mahieu, Eds., Reactive Sputter Deposition, Springer-Verlag, Berlin Heidelberg, 2008.

25 E. Habibi and H. Razmi, Int. J. Hydrog. Energy, 2012, 37, 16800-16809.

26 A. I. Ayesh, S. Thaker, N. Qamhieh and H. Ghamlouche, J. Nanoparticle Res., 2011, 13, $1125-1131$.

27 K. J. Stevens, B. Ingham, M. F. Toney, S. A. Brown, A. Lassesson, J. van Lith and S. C. Hendy, Mater. High Temp., 2007, 24, 211-216.

28 M. Khanuja, B. R. Mehta, P. Agar, P. K. Kulriya and D. K. Avasthi, J. Appl. Phys., 2009, 106, 093515.

29 A. Pundt, M. Suleiman, C. Bähtz, M. T. Reetz, R. Kirchheim and N. M. Jisrawi, Mater. Sci. Eng. B, 2004, 108, 19-23. 
M. Andersson and A. Rosén, J. Phys. Condens. Matter, 2010, 22, 334223.

31 S. M. Lang, I. Fleischer, T. M. Bernhardt, R. N. Barnett and U. Landman, J. Phys. Chem. A, 2014, 118, 8572-8582.

P. Brault, W. A. Chamorro-Coral, S. Chuon, A. Caillard, J.-M. Bauchire, S. Baranton, C. Coutanceau and E. Neyts, Front. Chem. Sci. Eng., In press.

33 A. N. Salanov and E. A. Suprun, Kinet. Catal., 2013, 54, 106-118.

34 M. Todorova, K. Reuter and M. Scheffler, Phys. Rev. B, 2005, 71, 195403.

35 E. A. Suprun and A. N. Salanov, Kinet. Catal., 2017, 58, 92-103.

36 E. D. German, M. Sheintuch and A. M. Kuznetsov, J. Phys. Chem. C, 2009, 113, 1532615336.

37 J. Kousal, O. Polonskyi, O. Kylián, A. Choukourov, A. Artemenko, J. Pešička, D. Slavínská and H. Biederman, Vacuum, 2013, 96, 32-38.

38 A. Caillard, M. El'Mokh, T. Lecas and A.-L. Thomann, Vacuum, 2018, 147, 82-91.

39 P. Andreazza, V. Pierron-Bohnes, F. Tournus, C. Andreazza-Vignolle and V. Dupuis, Surf. Sci. Rep., 2015, 70, 188-258.

40 P. Andreazza, in Nanoalloys, Springer, London, 2012, pp. 69-112.

41 J. Penuelas, P. Andreazza, C. Andreazza-Vignolle, C. Mottet, M. D. Santis and H. C. N. Tolentino, Eur. Phys. J. Spec. Top., 2009, 167, 19-25.

42 V. E. Ostrovskii and E. A. Kadyshevich, J. Therm. Anal. Calorim., 2017, 127, 819-850.

43 D. Depla, S. Mahieu and R. De Gryse, Thin Solid Films, 2009, 517, 2825-2839.

44 J. Söderlund, L. B. Kiss, G. A. Niklasson and C. G. Granqvist, Phys. Rev. Lett., 1998, 80, 2386-2388.

45 M. Villarica, M. J. Casey, J. Goodisman and J. Chaiken, J. Chem. Phys., 1993, 98, 4610-4625.

46 J. Kousal, A. Kolpaková, A. Shelemin, P. Kudrna, M. Tichý, O. Kylián, J. Hanuš, A. Choukourov and H. Biederman, Plasma Sources Sci. Technol., 2017, 26, 105003.

47 J. Polášek, K. Mašek, A. Marek and J. Vyskočil, Thin Solid Films, 2015, 591, 194-199.

48 A. Shelemin, O. Kylián, J. Hanuš, A. Choukourov, I. Melnichuk, A. Serov, D. Slavínská and H. Biederman, Vacuum, 2015, 120, 162-169.

49 S. Gauter, F. Haase, P. Solař, O. Kylián, P. Kúš, A. Choukourov, H. Biederman and H. Kersten, J. Appl. Phys., 2018, 124, 073301.

50 J. Blažek, J. Kousal, H. Biederman, O. Kylián, J. Hanuš and D. Slavínská, J. Phys. Appl. Phys., 2015, 48, 415202.

51 T. P. Senftle, R. J. Meyer, M. J. Janik and A. C. T. van Duin, J. Chem. Phys., 2013, 139, 044109.

52 R. Lamber, S. Wetjen and N. I. Jaeger, Phys. Rev. B, 1995, 51, 10968-10971.

53 W. H. Qi and M. P. Wang, J. Nanoparticle Res., 2005, 7, 51-57.

54 J. W. Arblaster, Platin. Met. Rev., 2012, 56, 181-189.

55 B. Lim, Y. Xiong and Y. Xia, Angew. Chem. Int. Ed., 2007, 46, 9279-9282.

56 F. Baletto and R. Ferrando, Rev. Mod. Phys., 2005, 77, 371-423.

57 S. Zhou, M. Zhao, T.-H. Yang and Y. Xia, Mater. Today, , DOI:10.1016/j.mattod.2018.04.003.

58 Y.-H. (Cathy) Chin, M. García-Diéguez and E. Iglesia, J. Phys. Chem. C, 2016, 120, 1446-1460.

59 R. Tran, Z. Xu, B. Radhakrishnan, D. Winston, W. Sun, K. A. Persson and S. P. Ong, Sci. Data, 2016, 3, 160080.

60 B. Roldan Cuenya and F. Behafarid, Surf. Sci. Rep., 2015, 70, 135-187.

61 A. B. Flores, L. A. Robles, M. O. Arias and J. A. Ascencio, Micron, 2003, 34, 109-118.

62 J. M. Thomas, P. A. Midgley, C. Ducati and R. K. Leary, Prog. Nat. Sci. Mater. Int., 2013, 23, 222-234. 
63 A. Mayoral, H. Barron, R. Estrada-Salas, A. Vazquez-Duran and M. José-Yacamán, Nanoscale, 2010, 2, 335-342. 